rapidly, it can lead to increased morbidity, increased mortality. Patients will stay in the hospital for a long time and may have some functional decline."

Alagiakrishnan is the lead author of a study that concluded health care professionals are not doing enough to identify the predisposing and precipitating factors that lead to delirium, a sentiment echoed by many in the field of geriatric medicine (Can Fam Physician 2009;55:e41-6). The study assessed 132 patients ages 65 and older who were admitted to medical teaching units at the University of Alberta Hospital over a seven-month period and found that 20 of those patients, or $15.2 \%$, developed hospital-acquired delirium.

"The focus is often on physical problems in hospitals and the mental side is not properly assessed," says Dr. Martin Cole, a geriatric psychiatrist at St. Mary's Hospital Center in Montréal, Quebec. "Some sort of systematic mental assessment would improve detection rates."

In some parts of Canada, hospitals have made changes necessary to improve delirium detection, notes Wong. In Vancouver, British Columbia and Edmonton, for example, hospitals have created "acute care for the elderly" units based on a model of elderly care which features multidisciplinary teams of specialists; elderly-friendly surroundings, including comfortable chairs and furnishings such as clocks with large faces and numbers; and policies designed to promote independence and cognitive stimulation, such as requirements that patients use bathrooms rather than bedpans and that they have their meals at central locations rather than in bed. In an effort to be elderly-friendly, other hospitals have introduced such measures as emergency room teams dedicated to detecting delirium or hired staff such as geriatric emergency nurses.

"In pockets, this is happening, but we need a more concerted movement," says Wong.

According to Wong, there's a need to better train medical students about detecting delirium. Because it is such a common problem, it should be added to the core competencies of medical students, he says. Other health professionals who work closely with seniors, including nurses and physical therapists, should also receive training in detecting and preventing the condition.

"We also need to look at systemic changes," says Wong. "We need to have a culture that will not only support the diagnosis of delirium but also provides resources to treat it."

Treating delirium involves providing good basic care, such as ensuring patients are getting enough fluids and nutrients. It also includes reorienting them to their surroundings. Family members should ensure elderly patients have their hearing aids, dentures, glasses or whatever else they need to engage their senses. Other things that can help include daily exercise, removing medications if possible and surrounding patients with familiar objects.

"We need to change how we are caring for patients in hospitals and get back to focusing on basic health care needs," says Dr. Jayna Holroyd-Leduc, an associate professor of geriatrics at the University of Calgary in Alberta. "In these days of high technology, we can forget that these are sick patients who need good basic care. They need to be properly hydrated and have appropriate nutrition. We have to encourage them to maintain their independence and keep them oriented to where they are."

In a recent paper, Holroyd-Leduc and colleagues found that most interventions for hospital-induced delirium involve strategies to optimize sensory input, improve orientation, provide familiar objects and encourage family visits (www.cmaj.ca/lookup/doi/10.1503/cmaj .080519). Health care providers would be wise to familiarize themselves with these and other strategies to treat and prevent delirium, because that knowledge is going to grow more valuable with each passing year, Holroyd-Leduc says. "As our population ages, we will see more and more delirium." - Roger Collier, CMAJ

CMAJ 2012. DOI:10.1503/cmaj.109-4069

\title{
Private rooms: A choice between infection and profit
}

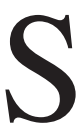
ome say it's trade-off between patient safety and psychological benefit.

Others say the evidence in support of private rooms in hospitals is inconclusive, while the more cynical suggest the ration of single-patient rooms to multi-patient rooms in hospitals is carefully designed to generate revenues.

But the growing incidence of hospital-acquired infections has the nation's nonprofit standard setting association calling for private rooms to become the norm in all hospitals built in Canada in the future so as to promote greater safety for patients.
The Canadian Standards Association (CSA) argues that a move toward single patient rooms is vital as nosocomial infections are becoming a deadly concern, with more than $50 \%$ of hospital beds in Canada now on wards with four or more beds per room. An estimated 225000 hospital-acquired infections occur annually, resulting in 8000 to 12000 deaths (Am J Infect Control 2003;31:266-73).

There's an $11 \%$ increase in the risk of Clostridium difficile infection, a $10 \%$ increase in the risk of methicillinresistant Staphylococcus aureus, and an $11 \%$ higher risk of vancomycin-resistant
Enterococcus infection with each exposure to a new hospital roommate, according to a recent study coauthored by Dr. Dick Zoutman, professor of microbiology at Queen's University in Kingston, Ontario, and chief of staff at the Belleville General Hospital in Ontario (Am J Infect Control 2010;38:173-81).

A move toward single patient rooms would be "wonderful," Zoutman says. "I think we've known intuitively for a long time that a private room is going to be safer accommodations for patients."

While opting to align Canada's guidelines with those of the United States, the United Kingdom and several Scandina- 
vian nations, the CSA indicated there may be clinical circumstances in which patients would benefit from the social and psychological advantages of shared rooms. That may be particularly true for select patient populations, such as those suffering from cancer or those in need of palliative care, says Doug Morton, CSA's director of health and safety.

"The more you can have single patient rooms, the better ... recognizing that in some cases ... it may be better for clinical reasons to have a patient in a room with multiple patients," Morton says. "So there probably would rarely be a hospital that would have $100 \%$ single patient rooms. So that's going to be dependent on the functional plan and the objectives of the institution."

Nevertheless, the new CSA standards would require that hospitals have valid supporting documentation in cases where they wish to retain multibed accommodations. In those cases, the new standard would also require one washroom per inpatient.

But Roger Ulrich, professor of architecture at Chalmers University of Technology in Gothenburg, Sweden, and a worldwide expert in health care design, says that "it's hard to cite any evidence anywhere that patients do better when they're with other patients."

"Social support comes from being with people who matter to you, not strangers," says Ulrich. "This is not Florence Nightingale where patients were in for six weeks and got pretty well and would look after the others. ... This is 2011."

"Even if one was to show some quality evidence from impartial research as opposed to anecdotal impressions, there are much better ways of handling it," he adds, arguing that all patients should be placed in single rooms for increased safety, while hospital wards should be redesigned to create more communal social spaces. "The reality is that much data from millions of patients internationally shows that roughly $90 \%$ if not more of patients consider having a roommate as a major source of stress."

Others, though, aren't entirely convinced that the evidence in support of single patient rooms is conclusive.

There's a need for more evidence

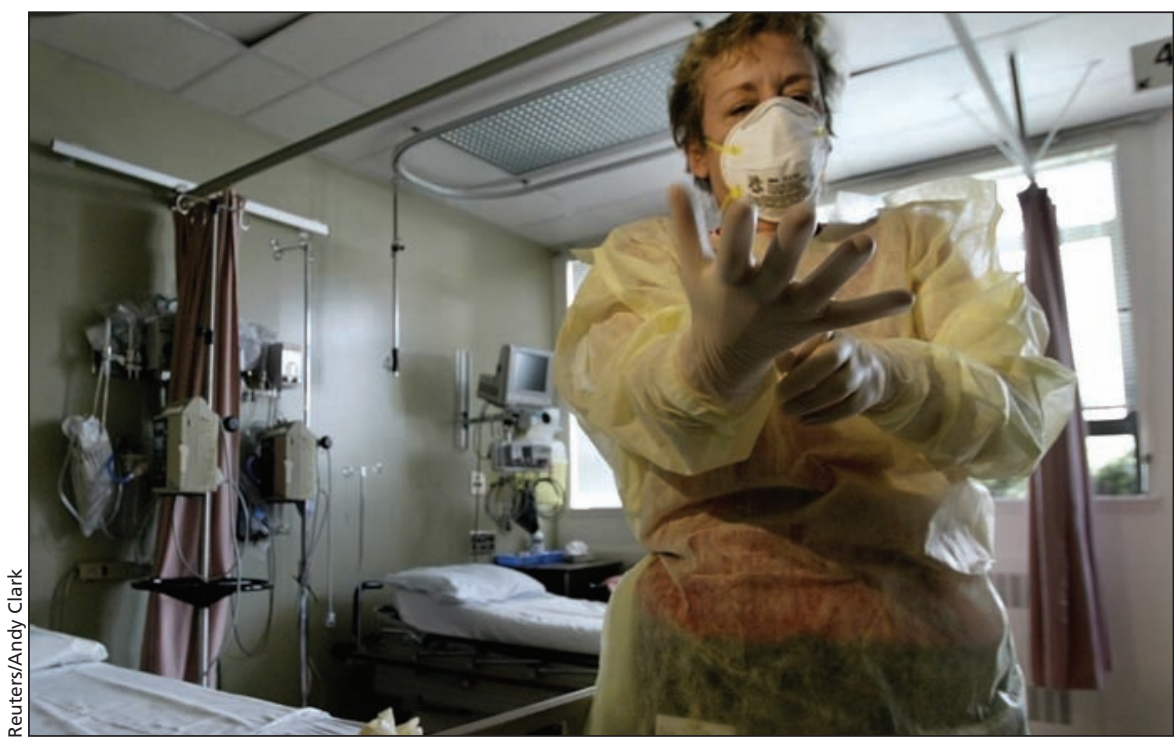

Hospital workers are required to don personal protective equipment when dealing with patients who have nosocomial infections.

that definitely proves that single patient rooms reduce hospital infection rates, says Pamela Fralick, president and CEO of the Canadian Healthcare Association.

"To the best of our knowledge, a Cochrane Review has not been done, so there is this question around where is the good science behind it. In fact the one study that we know about looked at this issue was from 2007 and it reported conflicting results in terms of the hospital infection rates," she says. (Editor's note: citation is Health Policy 2007; 84:153-61).

"That's impossible," counters Dr. Michael Gardam, director of infection prevention and control at the University Health Network in Toronto, Ontario. It "just doesn't make any sense."

"There's more than enough evidence to support $100 \%$ single rooms for hospital patients," adds the physician director of the Community and Hospital Infection Control Association - Canada, and leader of the STOP Infections Now Collaborative of the Canadian Patient Safety Institute. "I get a little bit annoyed with the people who say ... there's not enough evidence. There is evidence ... and I don't think you need the randomized controlled trial to prove that. Frankly, it's kind of common sense."

"I also wonder how many people who question this (100\% single rooms) have ever been hospitalized," Gardam says. "I actually have been hospitalized in my own hospital in a multi-bedded room and I can tell you it's not pleasant. You know you'd far rather be in a single room where the person beside you isn't dying, cause that's what happened to me right. It's a horrible experience."

That's consistent with studies indicating there are overwhelming benefits of single-bedded rooms on patient outcomes, including a systematic review conducted by Dr. Roger Ulrich and colleagues which indicated that singlebed rooms consistently outperform multi-bed rooms (www.healthdesign. org/sites/default/files/Role\%20Physical $\% 20$ Environ $\% 20$ in $\% 20$ the $\% 2021$ st $\% 20$ Century\%20Hospital_0.pdf). The advantages included reduced medical errors, fewer falls, improved patient confidentiality, privacy, sleep quality, doctor-patient communication and the ability to accommodate family members.

"It's the single most important design-related issue I know because single rooms are not only important for infection control, they are so important for so many other reasons," Ulrich says. — Nathan Stall, London, Ont.

CMAJ 2012. DOI:10.1503/cmaj.109-4077

Editor's note: First of a three part series.

Part II: Private rooms: Regulation and money

Part III: Private rooms: Evidencebased design in hospitals 